\title{
PALINOTECA FANEROGÂMICA NO ÂMBITO DO PROGRAMA DE PESQUISA EM BIODIVERSIDADE DO SEMIÁRIDO (PPBIO SEMIÁRIDO) Hemilly Marques Seixas ${ }^{1}$; Marcos da Costa Dórea²; Andrezza Lóren de Góes Nascimento $^{3}$; Reyjane Patricia de Oliveira ${ }^{4}$; Francisco de Assis Ribeiro dos Santos ${ }^{5}$ 1. Estagiaria voluntaria/ PEVIC, Graduanda do Bacharelado em Ciências Biológicas, Universidade Estadual de Feira de Santana, e-mail: hemillyseixas@ hotmail.com \\ 2. Orientador, Programa de Pós-graduação em Botânica (PNPD/CAPES), Departamento de Ciências Biológicas, \\ Universidade Estadual de Feira de Santana, e-mail: mcdorea@uefs.br \\ 3. Estagiaria voluntaria/ PEVIC, Graduanda do Bacharelado em Ciências Biológicas, Universidade Estadual de Feira de Santana, e-mail: andrezzaloren@gmail.com \\ 4. Departamento de Ciênicas Biológicas, Universidade Estadual de Feira de Santana, e-mail: rpatricia@uefs.br \\ 5. Departamento de Ciências Biológias, Universidade Estadual de Feira de Santana, e-mail: fasantos@uefs.br
}

PALAVRAS-CHAVE: palinologia; florística; angiospermas

\section{INTRODUÇÃO}

O desenvolvimento de estudos florísticos em hotspots no Semiárido do Nordeste é um dos principais objetivos do Programa de Pesquisa em Biodiversidade do Semiárido (PPBio Semiárido), os quais além de aumentar o conhecimento da flora regional, contribui fortemente para a formação de pessoal capacitado. Dados sobre a biodiversidade vegetal no Semiárido podem ser bastante ampliados, se analisadas as informações contidas nas coleções de herbários pouco acessados, além de muitos dados ainda não publicados.

Dentre as coleções biológicas, aquelas com material microscópico conferido em laminários - como as de grãos de pólen - são raramente priorizadas. Os grãos de pólen representam uma fase da vida de algumas plantas (Gimnospermas e Angiospermas) de reduzido tamanho e duração. Contudo, por serem portadoras em sua estrutura de uma substância única - a esporopolenina - que tem grande resistência química, sua "parede" pode resistir por milhões de anos em ambientes não-oxidativos (Traverse, 1988). Essa propriedade lhes confere importância como marcadores ambientais, pois é possível o estudo dos grãos de pólen e esporos da flora atual ou passada (fóssil) a partir de um estudo de sítios fossilíferos ou mesmo de sedimentos recentes ou qualquer outro material que os contenha. Assim, os produtos apícolas de todos os tipos, os sedimentos lacustres e até algumas rochas com material polínico incrustado podem ser estudados para, a partir de sua constituição palinológica, se tecer considerações associada à sua flora de origem.

Esse contexto atribui à coleção palinológica uma grande importância principalmente como uma biblioteca de referências para diversos outros estudos associados (GonçalvesEsteves et al., 2014). O momento atual tem exigido a elaboração de coleções biológicas também virtuais, nas quais são montados bancos de imagens disponibilizados on line para que qualquer pessoa tenha acesso a informação.

Sendo assim, principal objetivo dessa proposta foi a ampliação e elaboração de um banco de imagens para a Palinoteca da UEFS nos limites do Semiárido, incluindo diferentes grupos de fanerógamas, em áreas previamente selecionadas pelo PPBio Semiárido como prioritárias por serem detentoras de grande biodiversidade.

\section{MATERIAL E MÉTODOS}

Dentre as muitas áreas consideradas promissoras para o desenvolvimento de inventários de biodiversidade dentro do semiárido, o programa PPBIO Semiárido, em sua edição atual, selecionou as regiões entre Abaíra e Itaetê, no maciço central da Chapada 
Diamantina, no interior da Bahia; a região do sertão de Quixeramobim, com ênfase no município de Quixadá, no Ceará; e a região do baixo Jaguaribe, inserida na Chapada do Apodi, na divisa entre os estados do Rio Grande do Norte e Ceará.

Amostras previamente coletadas nessas áreas foram submetidas ao método da acetólise (Erdtman, 1960) para a retirada do conteúdo polínico. Em seguida foram montadas (no mínimo) três lâminas por amostra, sendo duas com gelatina glicerinada incolor e uma com gelatina corada com safranina, e por fim seladas com lamínula e parafina.

Todo o laminário foi incluído no banco de dados da Palinoteca da UEFS e acondicionado em caixas de madeira personalizadas que por sua vez serão depositadas em armários de aço da Coleção.

O laminário para cada espécie foi examinado em fotomicroscópio Leica, através do qual foram feitas as fotomicrografias. Futuramente todas as amostras registradas farão parte de um banco de imagens disponibilizado na internet.

\section{RESULTADOS E DISCUSSÃO}

Dentro do levantamento florístico do PPBio Semiárido foram disponibilizadas até o momento 113 amostras para a palinologia, das quais 98 já encontram-se incorporadas à palinoteca, sendo que 58 espécies tiveram seus grãos de pólen fotomicrografados. Isso representou ca. $60 \%$ do material do PPBio Semiárido, já depositado na palinoteca da UEFS, registrado em imagens.

Além do banco de imagens iniciado, há um incremento da coleção palinológica do Semiárido proveniente de áreas de coleta no âmbito do PPBio. Tanto o aumento da coleção quanto sua disponibilidade virtual é de extrema importância para demais estudo que utilizam a coleção como referência. Estudos em palinologia podem contribuir na elucidação de problemas relacionados a vários assuntos, como aqueles de cunho taxonômico e de biologia reprodutiva, assim como outros mais aplicados em melissopalinologia ou paleopalinologia (Silva et al., 2016).

Até o momento puderam ser fotomicrografados grãos de pólen de 26 famílias de Angiospermas: Acanthaceae, Amaranthaceae, Anacardiaceae, Asteraceae, Begoniaceae, Bignoniaceae, Bromeliaceae, Burseraceae, Cactaceae, Convolvulaceae, Eriocaulaceae, Euphorbiaceae; Lamiaceae, Leguminosae, Loganiaceae, Malpighiaceae, Malvaceae, Myrtaceae, Oxalidaceae, Passifloraceae, Phytolaccaceae, Plumbaginaceae, Poaceae, Portulacaceae, Rhamnaceae e Rubiacae.

\section{CONSIDERAÇÕES FINAIS}

O presente trabalho contribuiu principalmente com o incremento da Palinoteca da UEFS, uma importante coleção palinológica da região semiárida. As palinotecas de uma maneira geral são de grande importância em diversos estudos em que a palinologia é utilizada como ferramenta.

Desde o estudo das relações taxonômicas entre as plantas, àqueles que analisam insumos em que o grão de pólen é um importante marcador botânico e geográfico.

Portanto, juntamente com a importante missão do PPBio Semiárido, de realizar inventários florísticos em áreas prioritárias do bioma Caatinga, a montagem de um laminário palinológico de referência e seu banco de imagens, confere a esse programa de pesquisa a grande missão do registro de parte da megadiversidade brasileira.

\section{REFERENCIAS}

ERDTMAN, G. 1960. The acetolysis method. A revised description. Svensk Botanisk Tidskrift, Stockolm, 39: 561-564. 
GONÇALVES-ESTEVES， V.; MENDONÇA, C.B.F.; SANTOS， F.A.R. 2014. Coleções palinológicas brasileiras. Boletín de la Asociación Latinoamericana de Paleobotánica y Palinología 14: 83-88.

SILVA, F.H.M.; SANTOS, F.A.R.; LIMA, L.C.L. 2016. Flora polínica das caatingas: Estação Biológica de Canudos (Canudos, Bahia, Brasil). Feira de Santana, Micron Bahia, 120p.

TRAVERSE, A. 1988. Paleopalynology. Boston: Uniwin Hyman. 